\title{
Cartel internacional do estanho: a importância da indústria brasileira na quebra do conluio ${ }^{1}$ \\ Julio Cesar Cuter ${ }^{2}$ Anita Kon ${ }^{3}$
}

\begin{abstract}
Resumo
O presente artigo apresenta a indústria estanífera internacional como um oligopólio concentrado que se organiza em torno do International Tin Council, constituindo-se em um cartel com importante participação na formação dos preços do estanho, principalmente entre os anos 1960 e início dos anos 1980. Em virtude dos choques do petróleo e da crise internacional no final dos anos 1970, a associação dos produtores passa a ter dificuldades para administrar os interesses dos membros e gerir o estoque regulador, possibilitando a expansão de novos produtores. A indústria brasileira emerge neste cenário, aproveitando-se dos preços artificialmente elevados no mercado internacional, dos incentivos concedidos pelo governo brasileiro e das suas jazidas de boa qualidade, ampliando sua participação no mercado internacional, influenciando a quebra do conluio em 1985.
\end{abstract}

Palavras-chave: Estanho - Indústria; Oligopólios; Cartel.

\section{Abstract \\ International tin cartel: the importance of Brazilian industry in the breach of collusion}

This article presents the international tin industry as an oligopoly organized around the International Tin Council, making it a cartel with important participation in determining tin prices, mainly between the years 1960 and beginning of 1980. As a consequence of the oil shocks and the international crisis in the end of years 1970, the association of manufacturers began to have difficulties in managing the interests of its members and in controlling the buffer stock, facilitating the appearance of new producers. The Brazilian industry emerges in this scenario, benefiting from the artificial prices in the international market, from incentives granted by the Brazilian government and from its good quality mines, thus increasing its participation in the international market and contributing to the end of the collusion in 1985.

Key words: Tin industry; Oligopoly; Cartel.

JEL L130, D230, F130.

\section{Introdução}

A indústria estanífera mundial apresentou ao longo do século $\mathrm{XX}$ alta concentração de países produtores. Em 1982 (ano inicial do último acordo do

(1) Trabalho recebido em maio de 2006 e aprovado em setembro de 2007. Ligeiramente modificado do original apresentado no IV Ciclo de Debates em Economia Industrial, Trabalho e Tecnologia, do Programa de Estudos Pós-Graduados em Economia Política da Pontifícia Universidade Católica de São Paulo (PUC-SP) em 24 e 25 de abril de 2006.

(2) Mestre em Economia Política pela PUC-SP; Professor do Centro Universitário Senac (Serviço Nacional de Aprendizagem Comercial), São Paulo, SP, Brasil. E-mail: <julio.ccuter@sp.senac.br>.

(3) Pós-Doutorado pela University of Illinois at Urbana-Champaign (IUC/Illinois); Professora do

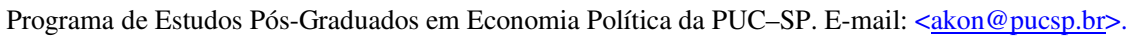


cartel de produtores), os quatro maiores produtores - Malásia, Indonésia, Bolívia e Tailândia - representavam juntos, aproximadamente, $75 \%$ da produção mundial.

Destacava-se, ainda, a pequena quantidade de firmas dentro de cada país explorando o principal minério do estanho, a cassiterita. Igualmente importante é considerar a integração quase completa da extração do minério com o seu beneficiamento metalúrgico, consolidando a cadeia produtiva, formando uma única indústria.

A intervenção direta no mercado do estanho, o conluio, tornou-se possível com o surgimento de condições propícias e objetivas: a concentração e a integração (Mitre, 1993). As primeiras tentativas de elaborar acordos fracassaram, mas com a criação de uma associação para gerir o cartel em 1931 e com a queda no preço do metal, consequiência da crise de 1929, as medidas de controle ganharam mais importância e começaram a surtir efeitos a partir de 1933.

Posteriormente, no entanto, mudanças impostas pelos dois choques do petróleo em 1973 e 1979 abalaram a indústria estanífera. O efeito inicial foi o aumento artificial do preço do metal elevando a rentabilidade dos produtores, conseqüentemente fortalecendo o cartel. Esta situação intensificou um processo de redução do consumo por parte dos países europeus e dos EUA, por meio da substituição por outros materiais e da introdução de novas tecnologias que visavam a reduzir o consumo do metal no seu principal uso, o revestimento de folha-de-flandres na indústria siderúrgica.

Em um segundo momento, o aumento dos preços no mercado internacional atraiu produtores, dada a rentabilidade oferecida pelos preços excepcionais alcançados, sobretudo, após o segundo choque. Como estes produtores, antes periféricos ou inexistentes, não integravam o International Tin Council (ITC), os países membros tiveram dificuldades para manter o cartel no comando das quantidades comercializadas no mercado internacional, levando a associação à bancarrota completa em 24 de outubro de 1985.

A produção brasileira se avolumou exatamente neste contexto. Os incentivos à indústria local antecederam ao primeiro choque do petróleo, no entanto, foi na segunda metade da década de 1970, período entrechoques, que a indústria ganhou incentivos mais consistentes dentro do II Plano Nacional de Desenvolvimento (PND), tomando impulso e destaque.

A produção de estanho no Brasil cresceu ininterruptamente até o final da década de 1980, alcançando, no triênio 1988-1990, a liderança mundial na produção (Alves, 1989). Nesse processo destacou-se também a crescente participação da Paranapanema, firmando-se como a principal indústria do setor no país, concentrando a produção e a comercialização internacional. 
O objetivo deste artigo é apresentar de forma bastante sucinta o cartel internacional do estanho para analisar a importância do crescimento da produção brasileira para o desmantelamento desse cartel. O trabalho está organizado, além desta introdução e das considerações finais, de seções que abordam a qualificação do oligopólio concentrado e do cartel, os efeitos do enfraquecimento das barreiras à entrada, a evolução da produção brasileira e, finalmente, os impactos e redesenho do mercado internacional.

\section{0 cartel de estanho: estrutura oligopolista}

O oligopólio é um tipo de estrutura de mercado intermediário entre o monopólio e a concorrência, mais comum que estes últimos, que são casos polares de estruturas de mercado. A característica básica do oligopólio é a presença de poucas firmas, que apresentam interdependência de ações, compondo a indústria.

A indústria oligopolizada apresenta uma variedade de classificações na literatura econômica; a mais tradicional das divisões apresenta-se em dois modelos: i) oligopólio puro: pequeno número de empresas produzindo produtos substitutos perfeitos; e ii) oligopólio diferenciado: prevalece um número restrito de empresas que são dotadas de poderes de mercado por produzirem produtos parcialmente diferenciados.

Labini (1986) propõe uma divisão distinta: i) oligopólio concentrado: produto homogêneo (ou pouco diferenciado) com um número restrito e variável no tempo, mas com uma quantidade muito reduzida de empresas que controlam a produção; ii) oligopólio diferenciado: concentração menor e elevado grau de diferenciação do produto; e iii) oligopólio misto: situação intermediária, ou uma combinação entre oligopólio concentrado e diferenciado.

A indústria estanífera enquadra-se perfeitamente na classificação de oligopólio concentrado utilizada por Labini, tanto em uma análise internacional como para uma investigação nacional. Esta característica, pequeno número de vendedores de produtos homogêneos, reforça a interdependência das ações e a percepção de poder de influência sobre os preços (Scherer, 1979).

Abre-se caminho para uma outra forma possível de segmentar o oligopólio, partindo da interdependência de ações criadas pelo pequeno número de empresas de grande porte que se colocam como rivais entre si. Esta situação pode levar a acordos que visam à maximização do lucro de todas as firmas em conjunto, em substituição ao lucro individual.

Segundo essa ótica, podem-se subdividir os grupos em dois: i) oligopólios coniventes: quando as empresas são coniventes na determinação de preços e de distribuição de mercado entre si. Podem organizar-se formalmente em uma 
associação - é o caso do cartel - ou não. Nesta situação, temos acordos informais e tácitos (gentlemen agreements); e ii) oligopólio não conivente: não organizado, ocorrendo ações independentes das firmas (Kon, 1999).

O cartel, prática econômica muito antiga, baseia-se em um conluio entre empresas rivais para ações comuns nos negócios, a fim de dominar o mercado e estabelecer um controle rígido sobre os preços. O conluio é um acordo entre empresas de um mercado a respeito de quantidades e/ou preços a serem produzidos (Scherer, 1979).

Os cartéis são freqüentemente internacionais e não existe a necessidade de que todos os produtores pertencentes a uma indústria integrem o cartel, mas, quanto maior o subconjunto de produtores, mais forte será o controle exercido. Para o sucesso, podem-se apontar dois elementos fundamentais: i) necessidade de estabilidade: ao firmarem um acordo, os participantes devem cumpri-lo firmemente; e ii) quanto maior o poder de mercado, mais vantajoso e fácil é a manutenção dos acordos (Pindyck; Rubinfeld, 1994).

O poder de mercado deriva da elasticidade preço-demanda, que tende a ser mais sensível para produtos homogêneos, como o estanho, sendo que os coeficientes das firmas individuais devem ser idênticos ao da indústria como um todo, tornando mais tênue a organização dos produtores. Em produtos homogêneos, a estrutura do setor é fundamental para a manutenção de preços que garantam lucros supranormais.

Conforme mencionado, a indústria estanífera caracteriza-se por um elevado nível de concentração, tanto na esfera nacional como internacional. $\mathrm{O}$ primeiro passo do setor na direção do cartel foi a articulação inicial dos dois principais produtores mundiais em 1920: Malásia e Índias Orientais Holandesas, ${ }^{4}$ tentativa que acabou frustrada, mas iniciou a articulação dos produtores. Esta primeira tentativa objetivava a manutenção dos preços após um aumento da produção em virtude das altas de preços observadas entre 1910 e 1920 (Alves, 1989).

Com a crise iniciada em 1929, os preços mundiais do estanho registraram acentuada queda, condição que facilitou a criação da Associação dos Produtores de Estanho (Hanan, 1983). Com o fracasso das primeiras tentativas de elevar o preço, em 1931 agregaram-se outros países e surgiu a International Tin Control Scheme (ITCS), que ficou mais conhecida pelo seu braço executivo, o ITC, que passou a ser o responsável, já em 1931, pelo primeiro grande acordo do setor (Mitre, 1993).

(4) Atualmente Indonésia. 
Quadro 1

Acordos internacionais de preço e produção do Estanho: 1920 a 1985.

\begin{tabular}{|c|c|}
\hline Vigência & Gestores do Acordo \\
\hline 1920 & Governos da Malásia e das Índias Holandesas Orientais \\
\hline 1929 & Governos da Malásia e das Índias Holandesas Orientais \\
\hline 1931 a 1933 & Governos da Malásia, Índias Holandesas Orientais, Nigéria e Bolívia \\
\hline 1934 a 1936 & Governos da Malásia, Índias Holandesas Orientais, Nigéria e Bolívia \\
\hline 1937 a 1941 & $\begin{array}{l}\text { Governos da Malásia, Índias H. Orientais, Nigéria, Bolívia, EUA e Reino } \\
\text { Unido }\end{array}$ \\
\hline 1953 a 1961 & ITC \\
\hline 1961 a 1966 & ITC \\
\hline 1966 a 1971 & ITC \\
\hline 1971 a 1976 & ITC \\
\hline 1976 a 1981 & ITC \\
\hline 1982 a 1985 & ITC \\
\hline
\end{tabular}

Fonte: Alves (1989).

A associação se configurou como uma ameaça à concorrência, uma vez que reunia os quatro principais países produtores: Malásia, Nigéria, Índias Orientais Holandesas e Bolívia. Somadas, as produções desses quatro países totalizavam 87\% da produção mundial em 1931. Posteriormente, outros produtores menores foram se associando. Entre 1937 e 1941 integravam o acordo os dois principais consumidores: EUA e Reino Unido (Quadro 1). Mais tarde, os EUA deixaram o ITC e passaram a agregar o estanho entre os minérios considerados estratégicos, criando um estoque regulador para o metal.

Até 1941, os acordos ainda eram liderados pelos países membros do ITC, no entanto, o primeiro acordo de estanho realizado no pós-guerra, firmado em 1953 e que vigorou até 1961, foi gerido diretamente pelo ITC e orientado segundo os desejos da Conferência das Nações Unidas para o Comércio e Desenvolvimento (UNCTAD). Os acordos sucederam-se a partir daí e, entre 1953 e 1982, houve acordos vigentes sem interrupção (Alves, 1989).

A associação foi a grande responsável pela formação do preço internacional do produto a partir de 1937, sobretudo entre 1971 e 1985, atuando com mais intensidade no principal mercado mundial de estanho: a London Metal Exchange (LME). 
A caracterização do cartel ficou completa com a percepção do desvirtuamento da proposta inicial do ITC que era de ajudar o desenvolvimento e crescimento econômico dos países produtores. Percepção derivada dos sucessivos aumentos sem justificativa econômica na década de 1970 (Gráfico 1), levando o estanho a uma posição de preços elevados e mais estáveis que os dos demais metais negociados na bolsa de Londres.

Nesse cenário, o mercado de estanho ganhou um importante vendedor: os EUA, que comercializaram com grande intensidade seu enorme estoque regulador na década de 1970 (Alves, 1989). Completando as dificuldades de manutenção do cartel, somaram-se, já no início dos anos 1980, os efeitos do segundo choque do petróleo e da crise internacional.

Mesmo com dificuldades crescentes, o cartel permaneceu com sua estratégia no último acordo que entrou em vigor em 1982: manutenção dos preços baseados em cotas de exportação dos países membros e estoque regulador. A essa altura, a política do ITC já não era mais coesa, condição fundamental para o sucesso inicial. Alves (1989) aponta, em 1985, último ano de vida da associação, estimativa de $10 \%$ da produção mundial sendo comercializada, por países membros, principalmente a Tailândia, fora da política estabelecida.

Outro fator que ajuda a explicar o fracasso do último acordo é a ausência dos dois principais expoentes na produção de estanho, a China e, principalmente, o Brasil. Estes dois países não tinham interesse em formalizar cotas de exportação baseadas no histórico do país, tendo em vista a etapa de expansão que suas indústrias passavam.

2 Efeitos do enfraquecimento das barreiras à entrada na formação dos preços do estanho

A existência de poucos e organizados produtores levou o setor a sucessivos planos entre 1920 e 1982 para valorizar o estanho, sendo que, a partir de 1953, esses planos passaram a ser coordenados pelo ITC. A quantidade restrita de produtores deve ser observada atentamente e associada às barreiras à entrada, que são os elementos que impedem a livre mobilidade de capital e que inviabilizam novos produtores.

Essas barreiras são mais que um simples impedimento de curto prazo; elas consistem em condições que determinam vantagens às firmas já estabelecidas. Bain (1956) aponta três barreiras: i) economia de grande escala (Economies of large scale), ii) diferenciação de produtos (Product differentiation advantages); e iii) vantagens absolutas de custos (Absolute cost advantages). 
É sabido que o número de empresas é determinante para o poder de monopólio das empresas e co-determinante do nível de preços e Labini elaborou um modelo que compatibiliza a idéia de custo pleno com a teoria das barreiras à entrada de forma dinâmica (Possas, 1987).

O preço é determinado por um complexo de forças que podem ser consideradas exclusivamente relacionadas com o setor produtivo como um todo, no qual o empresário opera. Os elementos fundamentais para se determinar o preço são: a) a extensão absoluta do mercado; b) a elasticidade da demanda; c) as diferentes tecnologias; e d) os preços dos fatores variáveis e das máquinas, os quais influenciam, juntamente com as tecnologias, na determinação do custo total médio das empresas (Labini, 1986).

Os elementos citados acima compõem um novo enfoque, o qual desconsidera o mecanismo de formação de preços baseado na premissa de o mesmo igualar-se ao custo marginal e à receita marginal, possibilitando, inclusive, a existência de mais de um preço de equilíbrio, possibilitando três situações: i) preço mínimo, que garante à empresa um retorno mínimo de capital; ii) preço de exclusão, que impede a entrada de novas empresas, pois não assegura a estas taxa mínima de lucro mínimo; e iii) preço de eliminação, inferior ao custo variável da concorrente, com o intuito de eliminá-la do mercado (Kon, 1999).

Não existindo possibilidade de discriminação de preços, ele será fixado o mais alto dentre as necessidades dos participantes, de forma a permitir que as empresas menos eficientes do oligopólio se mantenham produzindo e com a rentabilidade mínima exigida, o que, concomitantemente, garantirá às empresas líderes uma rentabilidade acima do normal.

Fatores que perturbem a ordem vigente nos custos das price leaders levam a mudanças na situação de equilíbrio, ajuste que visa a, simplesmente, recompor a taxa de lucro pela empresa líder ou modificar a estrutura da indústria. Outro fator determinante para o comportamento dos preços em situações de reestruturação da indústria é a fase do ciclo econômico: prosperidade, estagnação e depressão ou retomada (Labini, 1986).

O setor mineral experimentou grandes mudanças impostas pelos choques do petróleo, que proporcionaram, simultaneamente, um aumento nos custos de produção e uma elevação no preço das principais commodities ao longo da década de 1970. A fim de possibilitar a absorção da renda diferencial proporcionada por essas mudanças, o setor mineral procurou, por meio do aumento da escala de produção, reduzir seu custo; esta estratégia acabou aumentando a capacidade produtiva (Pereira et al., 1987). 
É importante destacar que a estratégia de ampliação da escala de produção chocou-se com uma realidade adversa, deparando-se com uma crise econômica de grandes proporções no início dos anos 1980. A indústria estanífera buscou, no aumento de preço controlado pelo ITC, a garantia da rentabilidade dos países membros, mantendo as cotas estáveis.

Esse aumento de preço fez com que o setor operasse em todas as minas dos membros do ITC, apesar da elevação do custo de produção que foi um reflexo, principalmente, do aumento do custo da energia. Os fatores supracitados, juntamente com a mudança na estrutura de custo, possibilitaram a expansão da quantidade de produtores marginais, o que acabou elevando a produção mundial em aproximadamente 9\% entre 1974 e 1980, contrariando a proposta de nãoelevação.

A partir de 1981, a crise econômica internacional afetou mais diretamente a demanda estanífera, refletindo na queda da produção. Com os preços em alta e a produção em queda, conforme Tabela 1, ocorreu a ruptura da articulação, aflorando as fragilidades do conluio. Essa situação levou a um acirramento da concorrência no interior da indústria, entre os produtores tradicionais (Pereira et al., 1987).

Tabela 1

Principais produtores mundiais de estanho em toneladas: 1974 a 1985

\begin{tabular}{c|c|c|c|c|c|c|c}
\hline Ano & Malásia & Indonésia & Tailândia & Bolívia & Brasil & Outros & Total \\
\hline 1974 & 68,12 & 25,62 & 20,34 & 30,15 & 3,56 & 35,62 & 183,42 \\
\hline 1975 & 64,36 & 25,35 & 16,40 & 31,96 & 4,51 & 38,47 & 181,05 \\
\hline 1976 & 63,40 & 23,42 & 20,45 & 30,32 & 5,47 & 36,98 & 180,05 \\
\hline 1977 & 58,70 & 25,92 & 24,21 & 33,62 & 5,76 & 40,16 & 188,37 \\
\hline 1978 & 62,65 & 27,40 & 30,19 & 30,88 & 6,33 & 39,12 & 196,57 \\
\hline 1979 & 63,00 & 29,44 & 33,96 & 27,78 & 6,64 & 39,05 & 199,87 \\
\hline 1980 & 61,40 & 32,53 & 33,69 & 27,28 & 6,93 & 37,99 & 199,82 \\
\hline 1981 & 59,94 & 35,27 & 31,48 & 29,82 & 8,29 & 39,90 & 204,70 \\
\hline 1982 & 52,34 & 33,80 & 26,20 & 26,77 & 8,23 & 47,61 & 194,95 \\
\hline 1983 & 41,36 & 26,56 & 19,94 & 25,29 & 13,28 & 48,32 & 174,75 \\
\hline 1984 & 41,31 & 23,22 & 21,60 & 19,91 & 19,96 & 44,76 & 170,77 \\
\hline 1985 & 36,89 & 21,76 & 16,60 & 16,14 & 26,51 & 40,02 & 157,92 \\
\hline
\end{tabular}

Fonte: Alves (1989).

Esse processo iniciado na década de 1970 e que representou grandes mudanças na década seguinte, inviabilizou o ITC, que acabou indo à bancarrota em 24 de outubro de 1985, deixando de honrar seus compromissos, levando à suspensão dos negócios com estanho na LME; neste contexto, o declínio de preços se estenderia por mais de 10 anos. 


\subsection{Processo de obtenção de economias de escalas}

Conforme Kupfer (2002), as vantagens de custos apontadas por Bain são particularmente freqüentes no caso de acesso a matérias-primas para indústrias extrativas, como o estanho. Todavia, de modo geral são consideradas pouco relevantes como barreira à entrada. Conforme aponta Stigler (1970), a qualidade superior de recursos naturais quase sempre é quebrada por descobertas de novas jazidas.

A condição natural apresenta-se como limitador, por serem os minerais recursos esgotáveis. No entanto, as perspectivas de descobertas de jazidas dependem diretamente do interesse em realizar investimentos em pesquisa mineral. A questão da exauribilidade das reservas ou fontes de minérios não deve ser tomada como uma variável exógena, já que ela depende das descobertas, que, por sua vez, são resultantes de uma decisão econômica de investimento (Postali, 2002).

A economia de escala reflete o declínio na distribuição dos custos indiretos, determinando a existência de uma economia mínima de escala para alcançar o ponto de equilíbrio. Esta condição pode impedir a instalação de uma nova empresa à medida que a elasticidade-preço é elevada. A pequena dimensão do mercado diante do tamanho ótimo da firma é outro elemento a ser considerado (Leftwich, 1973).

Evidencia-se a existência de barreiras à entrada quando a firma entrante tem que operar em uma escala inferior à mínima eficiente. Ou, ainda, ao instalar uma unidade de tamanho ótimo, seja obrigada a trabalhar com capacidade ociosa, para evitar uma queda nos preços (Oreiro, 1998).

As relações entre as grandes empresas é outro determinante neste ambiente; antecipar os efeitos que uma entrada terá sobre os preços e quantidades passa a ser vital (Possas, 1987). No cenário da indústria estanífera cartelizada, a entrada de uma nova grande firma, de um país sem tradição na produção, se daria em uma escala subótima ou deflagraria uma queda nos preços.

\subsection{Evolução da produção brasileira de estanho}

A produção de estanho no Brasil remonta ao princípio do século XX, no entanto, a exploração era realizada em pequenos depósitos aluvionares no Estado do Rio Grande do Sul (Abreu, 1937). A produção em escala industrial iniciou-se na década de 1940, ampliando-se na década seguinte; simultaneamente, a produção deslocou-se para o Estado de Minas Gerais.

Apenas a partir da exploração na região amazônica a produção brasileira começou a se avolumar e ganhar importância doméstica. Com a descoberta do 
minério em Rondônia, ainda na década de 1950, e com o início da produção na década seguinte, o país iniciou uma nova etapa; no entanto, internacionalmente, a posição continuou modesta, condição que deixou a produção brasileira às margens do ITC - o país não integrava a associação.

Os investimentos realizados nos anos 1970 e início da década seguinte foram bastante significativos, avolumando a produção brasileira de cassiterita e de estanho metálico, incluindo definitivamente o Brasil no panorama mundial de produtores - Tabela 1. Esses investimentos foram fruto de uma articulação de políticas públicas que buscaram desenvolver atividades dentro do PSI (Processo e Substituição de Importações).

O setor mineral aparece entre os destaques do programa no II PND, que se caracterizou, segundo Villela e Suzigan (1996), por apresentar planos e mecanismos formais de coordenação dos instrumentos e das políticas auxiliares entre si e com a política macroeconômica.

O II PND concentrou recursos, principalmente, em insumos básicos como siderurgia; química e petroquímica; papel e celulose; metais não-ferrosos e bens de capital (Monteiro F., 1994). O setor de metais não-ferrosos ganhou destaque com a tentativa de institucionalizar um conjunto de políticas específicas para o setor, que culminou com a criação do Conselho de Não-Ferrosos e Siderurgia (CONSIDER) em agosto de 1974, Decreto 74.361 (Rodrigues, 1997).

O setor de não-ferrosos figurava entre as matérias-primas importantes e carentes, cuja demanda interna causava déficits na balança comercial. $\mathrm{O}$ estanho apresentava situação singular: mesmo importando matéria-prima, o país conseguiu superávit comercial a partir de 1975, por possuir instalações metalúrgicas que possibilitaram a exportação de estanho metálico (Rodrigues, 1997).

Os investimentos viabilizados pelo II PND e a identificação de cassiterita em Pitinga, ${ }^{5}$ no Estado do Amazonas, possibilitaram um rápido avanço da atividade no país. No ambiente pós-choque do petróleo e ainda dentro do II PND, o governo passou a enxergar a região amazônica como fundamental, apontando para a ampliação do aproveitamento das expressivas riquezas naturais, especialmente minerais e energéticas (Lôbo, 1996).

A indústria estanífera nacional beneficiou-se das medidas de integração da região Amazônica com o pólo industrial do sudeste. Podemos mencionar como medidas importantes para o setor: i) instituição da Amazônia Legal e criação da Superintendência do Desenvolvimento da Amazônia (SUDAM); ii) criação do Banco da Amazônia S/A (BASA), em substituição ao Banco de Crédito da

(5) Mina localizada no Município de Presidente Figueiredo, no Estado do Amazonas, explorada pela Mineração Taboca S/A, empresa do Grupo Paranapanema S/A. 
Borracha; iii) introdução de importantes incentivos fiscais e modificação dos incentivos até então existentes; iv) criação da Zona Franca de Manaus (ZFM).

Essas medidas fiscais e parafiscais, somadas aos benefícios concedidos pelo II PND, auxiliam na explicação do rápido crescimento da produção brasileira de concentrado de estanho, passando de menos de $2 \%$ da produção mundial em 1974 para mais de 16\% em 1985, ano da quebra do ITC, conforme Tabela 1.

A primeira fase de expansão da produção de cassiterita brasileira (Gráfico 1), entre 1970 e 1980, ocorreu com o aumento da extração da reserva já conhecida de Rondônia, passando de pouco mais de 5 mil toneladas em 1970 para mais de 10 mil toneladas em 1980 (Empresas Brumadinho, 1983). Os elevados preços por um longo período facilitaram para que as reservas mais pobres produzissem marginalmente; a produção dessa região se expandiu nesse contexto.

\section{Gráfico 1}

Produção anual brasileira de cassiterita e Preço médio anual do estanho na LME no período entre 1974 e 1985

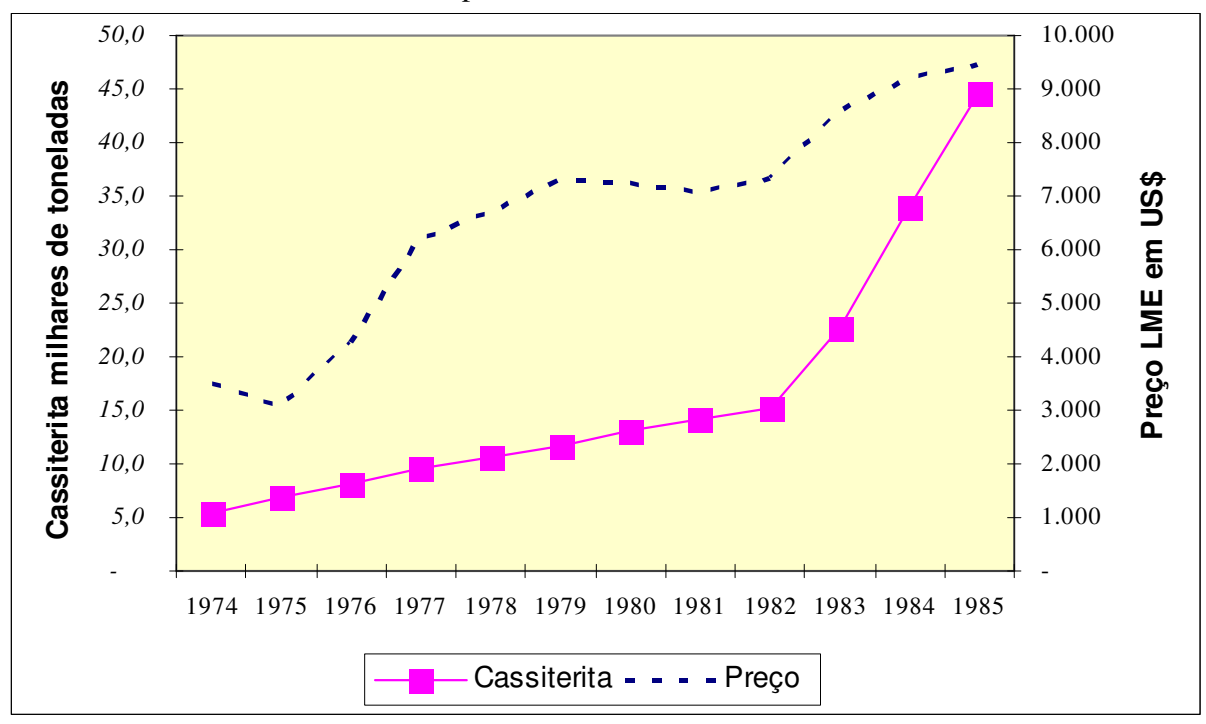

Fonte: London Metal Exchange e Rodrigues (1997).

As mudanças impostas nas condições de exploração da região, deixando de ser um garimpo e passando a ser uma extração industrial, foram fundamentais para explicar o rápido crescimento da produção em uma jazida madura (Hanan, 1983). Esta etapa refletiu o esforço realizado para obtenção da auto-suficiência, mas refletiu, também, a boa possibilidade para o setor privado, criada pelos preços elevados no mercado internacional. 
Os picos de cotação do produto alcançados no início dos anos 1980 favoreceram enormemente uma segunda expansão, que se beneficiou da descoberta de depósitos de cassiterita na região do rio Pitinga, fruto de um programa de reconhecimento geológico iniciado em 1974 (Rodrigues, 1997). Com a condição excepcional da mina do Pitinga, a indústria nacional alcançou rapidamente uma posição de destaque no conturbado cenário internacional, dificultando a política dos estoques reguladores do ITC, em virtude do baixo custo da mina brasileira e da facilidade de extração, possibilitando o rápido crescimento do Brasil no mercado.

Não obstante o grande investimento realizado durante a década de 1970, a produção brasileira concentrou-se significativamente na mina do Pitinga durante os anos 1980 (Rodrigues, 1997). Essa condição proporcionou ao país exportações em volumes crescentes na primeira metade da década, consolidando o Grupo Paranapanema como o principal produtor e exportador de estanho do país. A Paranapanema, que no ano de 1972 respondia por 34,93\% da produção nacional de estanho, passou em 1987 a responder por 70,84\% do total (Alves, 1989).

\subsection{Redesenho do mercado internacional}

A contextualização, inclusive histórica, da firma em um ambiente é condicionante não só para entender a estrutura da indústria, mas também para determinar a relação entre as firmas que a compõe (Bain; Qualls, 1987). O setor estanífero, além de alta concentração, apresentou histórico de conluio entre os tradicionais países produtores, com destaque para os países asiáticos.

Devemos considerar para a rápida expansão da produção brasileira o momento conturbado que modificou enormemente as condições internacionais em face dos choques do petróleo e suas consequiências na economia. Estas viabilizaram o início ou a expansão da atividade estanífera de alguns países, em especial do Brasil, por meio do enfraquecimento das barreiras à entrada e da desarticulação do ITC.

É necessário observar que, entre 1976 e 1981, a política do cartel conseguiu manter os preços em elevação, mas, no final do período, a participação dos países membros começou a apresentar queda na participação total; a partir de 1983, os efeitos da crise do mercado consumidor apresentaram-se de forma definitiva.

Esse momento, somado ao fato de o setor, àquela altura, ser considerado maduro, apresentando, inclusive, tendência de queda no consumo, explicam a decadência do ITC e a sua dificuldade em manter suas políticas de controle de preços. Isso veio a impossibilitar, também, a administração do estoque regulador. 
No caso de um cartel organizado, como o ITC, a entrada de uma nova firma na condição de price leader conduziu a um processo de acomodação grande, com quebra do cartel, queda nos preços e um longo período de reestruturação, que se estendeu por mais de 15 anos após a entrada em operação da mina de Pitinga.

O Brasil não pertencia ao ITC, conseqüentemente não participava dos acordos restritivos ao comércio do produto. De forma muito especial, do último acordo firmado em 1982, aproveitou-se dos altos preços para conseguir divisas, àquela altura de grande urgência para o país. $\mathrm{O}$ governo brasileiro recebia fortes pressões por parte dos países membros do cartel, mas, atendendo ao posicionamento dos produtores locais e a seus interesses de geração de divisas, o Brasil não participou do acordo.

Os produtores brasileiros pressionaram o governo para não aderir ao acordo, por acreditarem que por ser uma indústria relativamente nova no cenário internacional e não possuir uma posição consolidada, o acordo prejudicaria o potencial de crescimento do setor (Hanan, 1983). Os interesses casados do Estado e dos produtores levaram o Brasil a ficar fora do último acordo, sendo, àquela altura, o Brasil o terceiro maior produtor mundial, fator crucial para a quebra do ITC e um grande período de baixa nos preços internacionais.

\section{Considerações finais}

A indústria do estanho configurou um exemplo bastante elucidativo de elementos teóricos importantes presentes nas obras de Bain (1956) e Labini (1986), sendo os movimentos entre 1960 e 1985 muito ricos em todos os fatores para a análise completa das barreiras à entrada, do oligopólio concentrado e os seus impactos para a formação de preço.

A mudança imposta ao setor somada à decisão de manutenção de preços elevados alterou profundamente o funcionamento do cartel e, conseqüentemente, o equilíbrio vigente, enfraquecendo as barreiras à entrada, estimulando o abandono dos acordos e mudando a estrutura de custo dos países líderes.

Por sua vez, a indústria brasileira que, durante a década de 1970, recebeu estímulos para a pesquisa mineral e para a expansão do parque produtivo metalúrgico, deparou-se com uma condição excepcional, a de ampliar sua produção quando identificada a reserva de Pitinga. Isso aconteceu no auge dos preços no mercado internacional, com o cartel desarticulado e os principais compradores pressionando os membros pelos sucessivos aumentos.

Atendendo aos interesses nacionais, a crescente produção brasileira era colocada no mercado internacional, gerando divisas para o país, deteriorando o cenário mundial do setor. Este já estava enfraquecido pela venda de estoque regulador dos EUA, pela comercialização fora dos termos do acordo do ITC por 
países membros e pela situação econômica mundial. A somatória de toda a situação levou ao colapso do ITC em 1985, sendo indiscutivelmente a participação brasileira importante para o desfecho.

\section{Referências bibliográficas}

ABREU, S. F. A riqueza mineral do Brasil. São Paulo: Companhia Editora Nacional, 1937.

ALVES, A. M. Estanho: aspectos do setor produtivo no mundo (1970-1987), 1989. 158p. Dissertação (Mestrado em Geociências - Área de Administração e Política de Recursos Minerais)-Instituto de Geociências, Unicamp, Campinas, 1990.

BAIN, J. S. Barriers to new competition. Cambridge: Harvard University Press, 1956.

1987.

; QUALLS, P. D. Industrial organization: a treatise. London: Jai Press Inc.,

DEPARTAMENTO NACIONAL DE PRODUÇÃO MINERAL. Sumário mineral: Estanho. 2004. Mimeografado.

EMPRESAS BRUMADINHO. A indústria do estanho 1983/84. São Paulo, 1983.

HANAN, S. A. Panorama da mineração e metalurgia do estanho no Brasil e no mundo: subsídios para a elaboração da política setorial no país. Rio de Janeiro, 1983.

O reflexo da crise internacional do estanho para os países - Brasil. Rio de Janeiro: SNIEE. 1986, 4p. Mimeografado.

KON, A. Economia Industrial. São Paulo: Nobel, 1999.

KUPFER, D. Barreiras estruturais a entrada. In: KUPFER, D.; HASENCLEVER, L. (Org.). Economia industrial: fundamentos teóricos e práticos no Brasil. 2. ed. São Paulo: Editora Campus, 2002.

LABINI, P. S. Oligopólio e progresso técnico. 2. ed. São Paulo: Abril Cultural, 1986.

LEFTWICH, R. H. O sistema de preços e alocação de recursos. 3. ed. São Paulo: Livraria Pioneira Editora, 1973.

LÔBO, M. A. A. Estado e capital transnacional na Amazônia: o caso da Albrás-Alunorte. Belém: UFPA/NAEA, 1996.

MITRE, A. Cartelização do estanho: as duas faces do processo. Revista de Economia Política, São Paulo, v. 13, n. 2, p.146-152, abr./jun. 1993.

MONTEIRO F., D. C. O BNDES e seus critérios de financiamento industrial: 1952 a 1989. Dez. 1994. Disponível em: <http://bndes.gov.br/conhecimento/livro_ideias/livro17.pdf>. Acesso em: 7 jan. 2005.

OREIRO, J. L. A decisão de investir da firma: uma abordagem a partir da teoria das barreiras a entrada. Nov. 1998. Disponível em: $<$ http://www.joseluisoreiro.ecn.br/arquivos/arche.doc $>$. Acesso em: 18 jan. 2007.

PEREIRA, O. D. et al. Dois ensaios críticos: política mineral do Brasil. Brasília: CNPq, 1987. 
PINDYCK, R. S.; RUBBINFELD, D. L. Microeconomia. São Paulo: Makron Books, 1994.

POSSAS, M. L. Estruturas de mercado em oligopólio. 2. ed. São Paulo: Editora Hucitec, 1987.

POSTALI, F. A. S. Renda mineral, divisão de riscos e benefícios governamentais na exploração de Petróleo no Brasil. 2002. 120p. Dissertação (Mestrado em Economia)Universidade de São Paulo, São Paulo. 2002. Disponível em: $<$ http://gov.br/conhecimento/premio/pr241.pdf >. Acesso em: 7 jan. 2005.

RODRIGUES, A. F. S. O boom estanífero: fatores determinantes, efeitos e perspectivas, 1997. 124p. Dissertação (Mestrado em Geociências - Área de Administração e Política de Recursos Minerais)-Instituto de Geociências, Universidade Estadual de Campinas, Campinas, 1997.

SCHERER, F. M. Preços industriais: teoria e evidência. Rio de Janeiro: Editora Campus, 1979.

STIGLER, G. A teoria dos preços. 2. ed. São Paulo: Editora Atlas, 1970.

VILLELA, A. V.; SUZIGAN, W. Elementos para discussão de uma política industrial para o Brasil. Rio de Janeiro: Ipea, maio 1996. (Texto para Discussão, n. 421). 